This item was submitted to Loughborough's Research Repository by the author.

Items in Figshare are protected by copyright, with all rights reserved, unless otherwise indicated.

\title{
Can sport really help to meet the Millennium Development Goals? Evidence from children in Peru
}

PLEASE CITE THE PUBLISHED VERSION

http://dx.doi.org/10.1177/1527002516661601

PUBLISHER

Sage Publications / @ The Authors

VERSION

AM (Accepted Manuscript)

\section{PUBLISHER STATEMENT}

This work is made available according to the conditions of the Creative Commons Attribution-NonCommercialNoDerivatives 4.0 International (CC BY-NC-ND 4.0) licence. Full details of this licence are available at: https://creativecommons.org/licenses/by-nc-nd/4.0/

\section{LICENCE}

CC BY-NC-ND 4.0

\section{REPOSITORY RECORD}

Pawlowski, Tim, Ute Schuttoff, Paul Downward, and Michael Lechner. 2019. "Can Sport Really Help to Meet the Millennium Development Goals? Evidence from Children in Peru”. figshare.

https://hdl.handle.net/2134/21944. 


\title{
Can sport really help to meet the Millennium Development Goals? \\ Evidence from children in Peru
}

\begin{abstract}
In contrast to the popular policy claim that sport might serve as vehicle to meet the Millennium Development Goals, empirical evidence based on large-scale survey data is largely missing. We use panel data based on a cohort of children and employ propensity score matching to identify the effects of sports participation on child development in Peru. Our findings suggest that participation in a sports group has positive impacts on subjective health and a measure of social capital. However, and in contrast to developed countries, we find no statistically significant effects on well-being and human capital formation.
\end{abstract}

\section{JEL classification:}

C14, D12, I21, J24, Z29

\section{Keywords:}

Social capital, Human capital, Well-being, Health, Sports Participation, Development 


\section{Can sport really help to meet the Millennium Development Goals? Evidence from children in Peru}

\footnotetext{
"We at the United Nations know that sport is a universal language, uniting groups and nations across divides. Sport empowers youth, promotes good health and deepens UN values such as equality, mutual respect and fair play. Sport helps us in spreading messages of peace, driving social change and meeting the Millennium Development Goals (...)” (Ban Ki-moon, 2014a).
}

\section{Introduction}

Policy makers have traditionally embraced the role of sport in providing health and social benefits for both, adults and children - becoming manifest for instance in the European Sports Charter. Consequently, global organizations, such as the United Nations Children's Fund (Unicef), put much effort into fostering the implementation of Article 31 of the UN Convention on the right to play for children and adolescents. This has been emphasized in less developed countries (LDCs) since sport is seen as a low-cost but high-impact tool for child and youth development (Ban Ki-moon, 2014b).

In contrast to the belief in the beneficial effects of sports participation for children and adolescents in such policy initiatives, evidence based on the analysis of large-scale survey data is limited. The literature that exists, moreover, explores the outcomes of sports participation in developed countries (see Section II) where passive leisure activities such as watching TV are popular substitutes for physical activity, and employment as well as 
education possibilities to enhance human and social capital are widespread. This is different in LDCs where access to education is more limited (Caballero, 2005) and the conditions required to enhance social capital are worse (Bornstein et al., 2012). A final point of note is that the research that analyses the factors associated with child development in LDCs have not tested for causal relationships between sport and development. A recent example is Helmers \& Patnam (2011).

This paper contributes to the literature by formally testing for the presence of a causal relationship between sports participation and child development in Peru. Peru is interesting because it is still developing and involved in programs to increase children's sports participation. This is most notably through the Volunteer Sports Programs ${ }^{1}$ and the Sports Programs for (Disadvantaged) Children. $^{2}$ Moreover, the sports system has similarities compared to those in developed countries. In this respect there are coaches in many sports groups, which are often organized in clubs, and the most popular sport is football. ${ }^{3}$

The data used in the analysis covers a cohort of 658 children who had been surveyed in three periods about all areas of their life. ${ }^{4}$ The periods are: 2002, 2006 and 2009. While this data does not allow the observation of specific sports programs, it enables us to analyse the effects associated with general participation in sports through belonging to a sports group. By exploiting the panel structure of our data, and estimation by propensity score matching which, in contrast to linear and nonlinear regression models allows for flexible effect heterogeneity and is robust to a misspecification of the outcome equation, we argue that associations identified in the analysis have a causal interpretation. Our findings suggest that participation in a sports group has positive impacts on subjective health and a measure of social capital. However, and in contrast to the literature addressing developed countries, we do not identify any statistically significant effects of participation in a sports group on wellbeing and human capital formation. 
The reminder of the paper is structured as follows. We start with a discussion of the related literature in Section II. Information on the characteristics of Peru and its sports systems is presented in Section III. Section IV outlines the identification and estimation strategies employed, before discussing the results in Section V and drawing conclusions in Section VI.

\section{Literature Review: The Outcomes from Sport for Young People}

Unlike the growing literature based on large-scale survey data examining the outcomes associated with sports participation for adults (Cabane \& Lechner, 2015), there is relatively less research formally testing the effects of sports participation on young peoples' lives. Several studies have specifically focused on analysing the direct and indirect effects of curricular and extra-curricular formal sports participation, either in education or in clubs, on cognitive and non-cognitive skill formation. An overview is provided in Table A.1 in the Appendix.

Barron, Ewing, and Wadell (2000) made use of an instrumental variable (IV) approach to examine the effects of high school athletic participation on education and labour market outcomes in the US based on the National Longitudinal Survey of Youth. Private school, school enrolment, measures of health, family income, and location (central city) as well as information on the individual's height and weight at the time the individual was a high school

student were used as instruments. They found evidence that there is a direct impact of athletic participation on wages and educational attainment and argued that this reflects differences across an individual's ability or preference for leisure. However, some instruments are likely to have direct effects on their outcomes, for example the reputational impacts of the school, or the neighbourhood in which a child grows up could affect employment opportunities and 
are thus hardly credible. Further results are provided by Eide and Ronan (2001), who used an IV approach as well. They also used height as an instrument for participation. They showed that for white male students school-sponsored extracurricular sports participation has a negative effect on their educational attainment, but it has a positive effect for white female students.

In a study using data from the Michigan Study of Adolescent Life Transitions (MSALT) Eccles, Barber, Stone, and Hunt (2003) examined extracurricular activities and adolescent development. It was found that adolescent participation in school team sports is associated with better educational outcomes at grade 10 and 12. Furthermore, sports participants like school more and would rather attend college full time than is the case with none sports participants. However, only gender, intellectual aptitude, based on tests for verbal and mathematical abilities, and the mother's educational level were employed as control variables in the regression analysis. In contrast, a fixed effects strategy was used by Lipscomb (2007) to test whether sports activity provides an immediate return to student learning. Results showed that, independent of individual ability, athletic and other club participation in school are both associated with an increase in math test scores and with Bachelor's degree attainment expectations. Athletic club participation is also associated positively with science test scores. Finally, Stevenson (2010) made use of changes in US law, providing for equal provision of sporting opportunities for both male and female students, as a natural experiment to show that the post legislation increases in female sports participation increased female college attendance, employment and wages. The legal change involved Title IX of the Educational Amendments to the 1964 Civil Rights Act. This banned gender discrimination in federally funded educational institutions. The interaction of the Title IX legislation with preexisting levels of boys' sports participation formed the instrument for the change in girls' athletic participation over the period of 1972-1978. 
Besides these papers, which focus on the United States, three studies addressed the European context and, in particular, Germany. They focused on the wider impacts of sport than on just human capital. Pfeifer and Cornelißen (2010) analysed the impact of participating in extra-curricular athletic activities on the attainment of secondary school degrees and professional degrees. They used the 2000-2005 waves of the German SocioEconomic Panel to analyse individuals, aged between 17 years of age and 99 years of age, having finished their education and where retrospective information on their adolescence was available. The sample includes 2,930 males and 3,071 females. Ordered probit models with generalized thresholds were estimated and results showed that participation in sports activities has a significant positive impact on educational attainment. The robustness of the results is tested by applying an IV-approach using body height and city size as instruments.

Felfe, Lechner, and Steinmayr (2016) analysed the effect of sports club participation on skill development of children in Germany aged 3 to 10 years using data from the German Health Interview and Examination Survey for Children and Adolescents (KiGGS) as well as the German Child Panel (GCP). The effect of sport on children's cognitive skills, measured as the overall school grade, and non-cognitive skills measured by variables addressing emotional problems, behavioural problems, hyperactivity, peer problems, and antisocial behaviour, were estimated by employing matching methods. To avoid selection bias, a wide range of background characteristics were controlled for. The local availability of sports facilities was also included as an instrumental variable. Results showed that there is a positive effect of participation in sport on children's cognitive and non-cognitive skills. In addition to these effects, Felfe et al. (2016) found that children participating in sports clubs score higher on different health and well-being measures.

Finally, Gerlach and Brettschneider (2013) analysed the impact of sports club participation by children and adolescents on social capital, in particular social acceptance and 
respect by peers. Based on a longitudinal study of 1,637 individuals in Germany, and using variance analysis, they obtained a significant positive association between sports club participation by children or adolescents and social capital. They also obtained a positive relationship between sports club participation and well-being but no significant effect on obesity as a measure of health.

\section{Study Program and Institutional Background}

As the review of the existing literature suggests there is some evidence that sports participation in a variety of settings positively influences the development of young people in industrialized countries. In less developed countries, however, the conditions for the development of young people are generally different and certainly worse, at least when measured with resources available for fostering their development. For instance, children often grow up with malnutrition which is associated with poor developmental outcomes. ${ }^{5}$ In addition, some literature argues that there is a dearth of social capital such as limited interpersonal cohesion, social networks and availability of civil organizations (see, for example, Bornstein et al., 2012). Furthermore, manual labour and daily-survival activities demand high energy and physical inactivity is not a major problem (Caballero, 2005). These differences make it highly relevant to test, whether sports participation affects child development also in less developed countries, particularly in the context of claims by policy makers such as the UN.

The data used is taken from the Young Lives (YL) study program which is an international study of childhood poverty and was established to pursue the changing lives of 12,000 children over 15 years (2001-2016) in Ethiopia, India in the state of Andhra Pradesh, 
Peru and Vietnam (Young Lives, 2013). To create two age cohorts 2,000 infants, aged around 1 year, and 700-1,000 older children, aged around 8 years, were selected randomly in each country. International experts developed the interview questionnaires for the child, household and community levels which were used in all four YL countries (Crookston et al., 2011). ${ }^{6}$

Our study is focused on Peru since the country is involved in programs to increase children's sports participation. This suggests that the research questions addressed in this paper may have direct policy relevance. Moreover, the sports system in Peru has similarities to those in developed countries, for example there are coaches in many sports groups, which are often organized in clubs, and the most popular sport is the team sport of football (a summary of information on Peru is provided in the Appendix Tables A.2 and A.3). ${ }^{7}$ These similarities allow for a better comparison with previous findings from developed countries

In our study, the information was taken from the child questionnaires, answered by the child, and household questionnaires, answered by the primary caregiver. Only children from the older cohort who participated in all three rounds of the YL survey were analysed. This means that in 2002 they were aged around 8 years, in 2006 they were aged around 12 years, and in 2009 they were aged around 15 years. We decided to exclude children not enrolled in school in round $2(n=6)$ from the sample as it seems that their living conditions differ much from the rest of the sample. This leaves a sample of $n=658$ children for our analysis.

\section{Empirical Strategy}

In line with the few previous papers investigating causal effects of sports participation (for example Lechner, 2009; Downward, Hallmann, \& Pawlowski, 2014) a treatment effects analysis is conducted. In this study, the 'treatment' variable measures whether a child 
generally participates in a sports group or not. The examined outcomes include measures for human capital, social capital, subjective well-being and health capital. To establish causality in our setting we exploit the panel structure of the data, i.e. we take treatment and outcome variables from round 3 (r3) while potentially confounding variables are mainly taken from round 1 (r1) and 2 (r2). In what follows is a detailed description of the outcome variables before we present the identification and estimation strategies employed.

\section{Outcome Variables}

Human capital is measured by the Peabody Picture Vocabulary Test (PPVT). ${ }^{8}$ This test analyses receptive vocabulary and provides a quick estimate of verbal ability and scholastic aptitude (Pearson, 2013). In the test, a word is spoken and the child must choose the correct one of four pictures. Furthermore, in line with Becker (1962), who states that investments in schooling, on-the job training or medical care enhance individual productivity and therefore employment prospects, school enrolment is also included as indicator for human capital as a dummy variable.

Social capital is defined by Putnam as 'those features of social organization, such as trust, norms and networks that can improve the efficiency of society by facilitating coordinated actions' (Putnam, 1993, 167) and thereby 'enable participants to act together more effectively to pursue shared objectives' (Putnam, 1995, 664ff.). These networks can be broad and wide ranging (Downward, Pawlowski, \& Rasciute, 2014). Consequently, the feeling of safety can be included in the concept of social capital. Feeling safe can be established through social relationships. Having friends and being helpful as well as the presence of older pro-social role models can all contribute to a sense of safety (Caprara, Barbanelli, Pastorelli, Bandura, \& Zimbardo, 2000). Feeling safe is also influenced by public and neighbourhood safety. People do not feel safe when they are regularly surrounded by, or 
see, violence. Hence, feeling safe is strongly connected with the effectiveness of public safety in keeping violence in a community low (Overstreet \& Braun, 2000). In line with this, social capital is measured by neighbourhood trust, friends support and respect by other children and feeling safe outside the house (i.e. a safe environment) on a scale ranging from 1, (strongly disagree) to 5 (strongly agree). Finally, with respect to social capital, it should be noted that sports group participation could be a substitute or complement to other group participation and this is investigated in the research. For example, sport group participation may act to bond similar individuals together, thus reducing links to others, or bridge differences between individuals. The latter is often cited as important for producing social cohesion, but bonding capital can be also important. For instance, Seefeldt and Erwing (1997) argue that sports participation is a substitute to gang behaviour as adolescents join gangs because they provide an identity for its member and serve many functions that a family might do. Here other group participation is measured by dummy variables of memberships in after school, religious, school and youth groups.

Subjective well-being can be measured as the emotional response and global judgment of life satisfaction, happiness, eudemonia or good psychological functioning (Hornung, 2006). Although there are differences in the definitions of these terms, life-satisfaction and happiness are often used as synonyms. In this study, subjective well-being is measured as satisfaction with life where children should state their current position on a ladder ranging from step 1 to step 9. Higher steps denote higher satisfaction with life. The ladder, as a representation of well-being, was first developed by Cantril (1965).

Health capital is measured as subjective health status and Body Mass Index (BMI). The question on the health status has to be answered by the children on a 5-point scale (1=very poor to 5=very good). The BMI is calculated by dividing weight by squared height. 
Table 1 provides descriptive statistics for the outcome variables available by treatment and control group membership including t-tests of mean differences. The results indicate significant differences with regard to the average achievements in the vocabulary test, the portion of children feeling that their friends will stand by them during difficult times as well as the children's subjective well-being and health status. However, just comparing the outcomes of children participating with those not participating in a sports group might yield biased results if those two groups differ with respect to other characteristics that also influence the outcome variables. To identify the effects of sports group participation, it is necessary that three central assumptions hold.

\section{Identification}

The first assumption is known as the no confounding or conditional independence assumption (CIA), the second is known as the stable unit treatment value assumption $(\mathrm{STUVA})^{9}$ and the third is known as common support or overlap assumption (OVERLAP) ${ }^{10}$ (Imbens, 2004).

The CIA implies that potential outcomes are conditionally independent of the treatment, which is sports group participation, for given values of any confounding variables $X$ that might influence both. As noted in Section II, since previous studies confirm that selection into sport is not random, it is likely that a selection bias exists in the context of our study. Therefore, we need to control for variables jointly determining sports group participation and outcome variables. These confounding variables are used to estimate the conditional choice probabilities of being a sports group member, that is the propensity score (see Rosenbaum \& Rubin, 1983), before matching similar individuals that just differ with 
respect to the treatment who can thus form the basis of a causal analysis. Thus, finding these variables is crucial for a causal interpretation of the estimates obtained with such a method.

In general, finding relevant and exogenous ${ }^{11}$ confounders is not straightforward. Therefore, our choice of confounding variables is based on theoretical considerations and previous empirical findings related to sports club participation in developed countries since there is no study available, which focusses on sports participation in less developed countries. To avoid problems of endogenous confounders we use variables primarily from the period prior to the treatment and the outcomes, i.e. from r1 or r2. Table A.4 in the Appendix provides a description of all confounding variables used in the analysis.

The first block of variables covers socio-demographic features and child environmental characteristics, gender and the urban/rural context. The literature indicates the importance of controlling for gender (for children see McHale, Crouter, \& Tucker, 2001). The urban or rural context is included here since it appears plausible that urban areas in less developed countries might have a better provision of sports facilities than rural areas, which may influence sports activity in general (for example Huang \& Humphreys, 2012). To describe the background and environment of the children, variables characterizing the household and parents are taken into consideration. The household is represented by its size. Studies have found that adult sports participation is reduced by having children in a family especially for females (for example Downward \& Riordan, 2007). Further results show that there is a relationship between sports participation of children and their parents and siblings (for example Scheerder, Taks, \& Lagae, 2007; Downward et al., 2014). In addition, household wealth compared to other households, measured as a dummy variable, with 'richer or average' as the reference category, and a wealth index are included. The latter measures the socioeconomic status of a household and incorporates housing quality, for example the number of rooms per person, consumer durables and services, for example the availability of 
electricity or water (Kumra, 2008). Previous studies showed that higher socio-economic status and higher incomes raise sports activity (Lechner, 2009). The relationship between primary caregiver and child, as well as the educational level of the primary caregiver are also included in the list of variables. Finally, time-use variables (leisure, chore, study, sleep) are included to measuring the hours spent engaging in leisure, chores, studying and sleeping per day (Humphreys and Ruseski, 2011).

The rich data available allows us to control for several of the most important confounding factors. However, we are not able to control for further potentially confounding factors like genetics, psychological, cognitive and emotional factors or behavioural attributes, since this information is either not observable in general or not available in the data. What is available in the data, however, is information from earlier survey rounds ( $\mathrm{r} 1$ and $\mathrm{r} 2$ ) on several outcome variables, i.e. lagged outcomes. If we assume that most of the aforementioned factors are stable over time and influence the outcome variables under consideration, then we can assume that they already influenced past outcomes as well. Therefore, to control for such unobservable factors, lagged outcomes are included. Unfortunately, some of these variables are either measured differently in previous rounds compared to round 3 or they are not available in round 2. Human capital is measured by work in round 2, reading and writing in round 1, numeracy skills in round 1 and scoremath in round 2. Reading, writing and numeracy are included as dummy variables with the reference categories being having the ability to read/write/calculate. Scoremath is measured by a test where children have to solve ten arithmetic problems in which scores between 0 and 10 can be achieved. Furthermore, neighbourhood trust, respect by children and safe environment are included as lagged social capital measures. The variable friends support is not available in round 2. Subjective health status was measured as compared to other children and a dummy for long-term illness was included with the reference category no long-term illness to 
measure health capital. Further, body mass index from round 1 is included as well as height which is taken from round 3 (at the age of 15) as it is assumed, as with the literature in Section II, that height is not affected by sports activity of children, at least in the short run. However, height can have an effect on the physical activity of children (Barron et al., 2000). Finally, dummy variables for group memberships in after school-, religious-, and informal child groups are also used as confounding variables.

Summing up, we argue that the use of the confounding variables described above reveals the best possible evidence from this data about the effect of sports group participation on the outcome measures of interest.

\section{Estimation}

Since treatment effects in general might be heterogeneous, we estimate and compare three effects, i.e. the average treatment effects (ATE), the average treatment effects on the treated (ATET) and the average treatment effects on the non-treated (ATENT) (see Imbens \& Wooldridge, 2009). In this regard, ATE measures the expected effect for a randomly selected child from the whole population. This includes all children who participate in a sports group and children who do not participate in a sports group. In contrast, ATET only measures the expected effect for those who get the treatment. This is children who participate in a sports group. Finally, ATENT measures the expected effect just for those who don't get the treatment. This is the children who do not participate in a sports group.

These effects are estimated by radius matching based on the propensity score. This method enables comparison of the different outcomes of children being a member of a sports group, as treated individuals, with the outcomes of children who are not a member of a sports group. To avoid selection bias, the two groups are adjusted in their covariate composition 
based on the propensity to be member of a sports group, which is estimated using a probit model. $^{12}$

Specifically, we apply an estimator that takes into account the methodological considerations of Lechner, Miquel, and Wunsch (2011). Compared to standard nearest-neighbour matching this procedure is more precise because it uses as many observations as are available within a certain radius and averages similar observations. This implies that more than one neighbour may be used to compute the 'matched' control outcome for a treated (see for example Dehejia \& Wahba, 2002). Furthermore, the algorithm uses the initial matching weights in a second step of weighted regression adjustment, which has two advantages. Firstly, the estimator satisfies a so-called double robustness property: it remains consistent if either the matching step is based on a correctly specified selection model, or the regression model is correctly specified (for example Rubin, 1979; Joffe, Ten Have, Feldman, \& Kimmel, 2004). Secondly, the regression adjustment should reduce small sample as well as asymptotic biases of matching (see Abadie \& Imbens, 2008). Huber, Lechner, and Wunsch (2013) investigate the finite sample properties of this radius matching with bias adjustment algorithm along with many other matching type estimators and find it to be most highly ranked.

Concerning inference, Abadie and Imbens (2008) show that for standard matching, that is based on a fixed number of comparison observations, bootstrap-based inference may be invalid. However, the matching algorithm used in our analysis is smoother than the one studied by Abadie and Imbens (2008) because it is based on a variable number of comparisons and uses regression adjustment. For this reason, the bootstrap is likely to be a valid inference procedure in our context. To take account of the panel nature of the data, a block bootstrap is used in which all observations of the same individual over time form the block. To be more precise, inference is based on (i) bootstrapping the sample 4,999 times; (ii) computing the t- 
statistics of the respective average effects in each of the bootstrap samples (normalized by the estimated effect); and (iii) estimating the p-value as the share of absolute bootstrap t-statistics that are larger than the absolute t-statistic in the original sample (see for instance MacKinnon (2006) for a discussion on bootstrapping symmetric statistics). This statistic is smoothed as suggested by Racine and MacKinnon (2007). Since the theoretical results by Abadie and Imbens (2008) and the simulation based results in Huber et al. (2013) suggest that the estimator is asymptotically normally distributed, bootstrapping the potentially pivotal tstatistic, computed under the assumption that the weights obtained to compute the control group are non-stochastic (see Lechner, 2002), has the advantage of potentially providing socalled asymptotic refinements and thus improving inference. In addition, we also checked the bootstrap distribution of the estimated effects directly using the quantile method. The results are very similar and available on request.

\section{Results}

Since just comparing the outcomes of children participating with those not participating in a sports group might yield biased results if those two groups differ with respect to other characteristics that also influence the outcome variables, results such as simple comparisons presented in Table 1 will be misleading and must be treated with caution. In this section we present the estimation results based on the identification strategy as laid out above to identify, as much as possible, causal effects. We start with discussing the estimates of the probit model for the variables of the selection process into sports group participation before providing the matching results of ATE, ATET and ATENT.

For ease of exposition, Table 2 provides an (abbreviated) overview of the mean values by treatment state and the selection-into-sports-group probit model. ${ }^{13}$ 
There are slightly less males than females in the sports group sample (49\%) compared to the non-sports group sample (54\%). However, in line with the balance of gender, there is no association of being male with the probability to participate in a sports group. Interestingly, $42 \%$ of the sports group sample lives in urban sites whereas the figure for those who don't participate in a sports group is much higher (64\%). According to the probit analysis there is a significant and negative association between living in urban areas and sports group participation. Furthermore, the percentage of households, which assess themselves as poorer, compared to other households, is slightly higher in the sample of non-sports group members. Correspondingly a poorer household situation is significant and negatively associated with the probability of participating in a sports group. However, the objective measure of wealth by the wealth index shows no significant association with participation.

In addition, being in a sports group in round 2 is highly significant and positively associated with being in a sports group in round 3. This is perhaps not surprising as $58 \%$ of those who are in a sports group in round 3 have already been in a sports group in round 2 . With regard to time allocation, there are significant positive associations of leisure, study and chore time with the probability of participation in a sports group in round 3, as well as having done paid work in the last 12 months. Finally, a positive association of being in a religious group with participating in a sports group can be observed.

\footnotetext{
*** Table 3 about here $* * *$
}

Table 3 provides the matching results of following effects: ATE, ATET and ATENT. Since common support is given for more than 98 per cent, the overlap assumption is not of 
concern. In line with the results of the simple t-tests of mean differences in the subsamples (Table 1), we find a significant effect of sports group participation on subjective health status and a measure of social capital (perceived support by friends in difficult times). These findings are in line with previous findings from developed countries. For instance, Felfe et al. (2016) also found that children's (subjective) health and physical well-being in Germany is rated significantly better among sports active children. These findings were confirmed in their study with objective measures. With regard to social capital, Felfe et al. (2016) found reduced problems with peers and a better feeling among friends when doing sports which is comparable to our outcome variable 'perceived support by friends in difficult times‘. Gerlach and Brettschneider (2013) also support this finding for children and adolescents aged 7 to 17 years where participating in a sports club is positively associated with social acceptance and respect by peers. Furthermore, our results suggest, that unlike in developed countries sports group participation may have much less relevance to human capital outcomes through education and consequently the labour market, and also subjective well-being.

\section{Conclusions}

The literature for the US and some European countries suggests a broadly positive impact of sport on human capital, social capital, well-being, and health. This is different in our setting. In contrast to developed countries, we do not find any statistically significant effects on well-being and human capital formation. However, sports club participation has positive impacts on children's subjective health and a measure of social capital. Therefore, these results suggest that sport can influence two of the key factors that are central to children's development (Bornstein et al., 2012) and, importantly, establish this by analysing largescale survey data of a carefully selected country-wide sample. 
Overall, our results suggest that some of the aspirations of development aid organizations can be met through sport as this paper provides support for the use of sport to reach at least some of their policy targets. That sports participation does not appear to affect children's well-being or their human capital in our setting is an issue that is of concern. One possibility is that these are more individual impacts of sport and the fact that we are examining sport that takes place in groups may mean that either the form of participation is biased in favour of social and group outcomes or that, in contrast to developed countries, sport as a development tool is much more connected with group outcomes than individual outcomes, except in the context of health. This is implied in Section III. In developed countries, however, it is plausible that the impacts of activities on individuals are different. Individuals may have the income and opportunity to choose engaging in sport to meet their personal desires. It could also be that educational establishments routinely provide opportunities to engage in sport as part of well-established informal pathways into labour markets. This means that the cultural and institutional context is different. These differences connected with the specificity of a country and the dependence of the effects of sports group participation on the quality and format of the sports organization are issues for future research.

\section{Notes}

1. The aim of this program is to involve (young) people from abroad helping to teach children and adolescents aged 6 to 17 years a variety of sports in sports clubs/sports centres and at schools: http://www.volunteersports.co.uk/sports/school-sports/peru/

2. The aim of this program is to provide a complement to the public education system for children and adolescents aged 6 to 15 years with physical and technical training for a sport as well as measures for educational and general development: http://proxied.changemakers.net/journal/02april/wolf.cfm

3. Football in this paper refers to European football, i.e. soccer.

4. The data used in this publication come from Young Lives, a 15-year study of the changing nature of childhood poverty in Ethiopia, India (Andhra Pradesh), Peru and Vietnam (www.younglives.org.uk). Young Lives is corefunded by UK aid from the Department for International Development (DFID) and co-funded from 2010 to 
2014 by the Netherlands Ministry of Foreign Affairs. The views expressed here are those of the author(s). They are not necessarily those of Young Lives, the University of Oxford, DFID or other funders.

5. For instance, Victora et al. (2008) show for cohort studies from Brazil, Guatemala, India, the Philippines, and South Africa that poor fetal growth or stunting in the first two years of life result in irreversible damage, for example shorter adult height, lower attained schooling, and reduced adult income. Further, malnutrition in early childhood can cause vocabulary deficits (Grantham-McGregor, 2002) and other deficiencies in school performance and intelligence (Grantham-McGregor, 1995). Alderman (2010) argues that early childhood nutrition is a long-term investment in health, nutritional and cognitive development. However, Crookston et al. (2011) point out that poor nutritional status alone does not account for children's cognitive deficits. Their study confirms that other factors such as wealth, maternal education, area of residence and number of siblings are also important determinants of verbal and quantitative ability. In line with this, Ghuman et al. (2005) indicate that family background (for example family's physical assets) has important positive effects on early child development in the Philippines.

6. Some papers have already made use of the YL study program data (see Helmers \& Patnam, 2011, or Lordan \& Frijters, 2013, as an example).

7. All information on sport and sport systems in Peru were provided by interviews and discussions with Virginia Rey-Sánchez (Directora de comunicaciones; Estudio Niños del Milenio) as well as Mariluz Aparicio (Asistente de comunicaciones; Estudio Niños del Milenio). If not indicated otherwise, numbers are taken from the World Factbook (2013).

${ }^{8 .}$ In Peru, the Spanish version of the PPVT-R, the Test de Vocabulario en Imagenes Peabody (TVIP), was used. Before implementing the tests into the study, they were translated into each country's main languages by the local team and verified by a local expert (Cueto, Leon, Guerrero, \& Muñoz, 2009).

9. STUVA demands that potential outcomes are unaffected by the particular assignment of the treatment. This condition requires that there are no unrepresented treatments (everybody is either 0 or 1 ) and that there are no relevant interactions between treatments (the fact that child $i$ participates does not change the potential outcome of child $j$ ). We think that this assumption holds in our context at least with regard to an individual's perception of their experience. However, some spill-overs could be latently present.

10. By estimating treatment effects the probability of the treatment (denoted by $w$ ) assignment given covariates, $X$, (propensity score $p(x):=P(w=1 \mid X=x)$ ) is important. The overlap (or common support) assumption forecloses the possibility that $p(x)$ is ever zero or one which means that the perfect predictability of treatment given a set of confounding variables $X$ is ruled out (Imbens \& Wooldridge, 2009). This ensures that for any given value of the confounding variables, a unit could potentially be observed with $w=1$ or $w=0,0<$ $p(x)<1$. As indicated by our results we generally deal with a set of observations with appropriate matches.

${ }^{11 .}$ For instance, while sports group participation might positively affect health status, children are in general more likely to be physically active (and organized in sports groups) if they do not suffer from health problems.

12. For estimation, Bin_Match_4.0.1 is used, which is the Gauss version of the radius match command in STATA (see Huber, Lechner, \& Steinmayr, 2015, for an investigation on the sensitivity of the estimator with respect to different values of various tuning parameters). It is used on Gauss Version 13. The Gauss program 
can be downloaded from www.michael-lechner.eu/software, while Stata and R versions are available from the respective repositories.

13. The complete version is available on request. 


\section{References}

Abadie, A., \& Imbens, G. W. (2008). On the Failure of the Bootstrap for Matching Estimators. Econometrica, 76(6), 1537-1557.

Alderman, H. (2010). The economic cost of a poor start to life. Journal of Developmental Origins of Health and Disease, 1(1), 19-25.

Barron, J. M., Ewing, B. T., \& Wadell, G. R. (2000). The effects of high school athletic participation on education and labour market outcomes. Review of Economics and Statistics, 82, 409-421.

Becker, G. S. (1962). Investment in Human Capital: A Theoretical Analysis. Journal of Political Economy, 70(5), 9-49.

Bornstein, M. H., Rebello Britto, P., Nonoyama-Tarumi, Y., Ota, Y., Petrovic, O., \& Putnick, D. L. (2012). Child development in developing countries: Introduction and Methods. Child Development, 83(1), 16-31.

Caballero, B. (2005). A nutrition paradox - underweight and obesity in developing countries. The New England journal of medicine, 352(15), 1514-1516.

Cabane, C., \& Lechner, M. (2015). Physical activity of adults: a survey of correlates, determinants, and effects. Jahrbücher für Nationalökonomie und Statistik (Journal of Economics and Statistics), 235(4+5), 376-402.

Cantril, H. (1965). The pattern of human concerns. New Brunswick: Rutgers University Press.

Caprara, G., Barbanelli, C., Pastorelli, C., Bandura, A., \& Zimbardo, P. (2000). Prosocial foundations of children's academic achievement. Psychological Science, 11(4), 302306. 
Classbase. (2013). Education System in Peru. Retrieved August 23, 2013 from http://www.classbase.com/Countries/Peru/Education-System

Crookston, B. T., Dearden, K. A., Alder, S. C., Porucznik, C. A., Stanford, J. B., Merrill, R. M., Dickerson, T. T., \& Penny, M. E. (2011). Impact of early and concurrent stunting on cognition. Maternal and Child Nutrition, 7(4), 397-409.

Cueto, S., Leon, J., Guerrero, G., \& Muñoz, I. (2009). Psychometric characteristics of cognitive development achievement instruments in round 2 of Young Lives (Young Lives Technical Note No.15). Retrieved August 23, 2013, from http://www.younglives.org.uk/files/technical-notes/psychometric-characteristicsofcognitive-development-and-achievement-instruments-in-round-2-of-young-lives.

Dehejia, R. H., \& Wahba, S. (2002). Propensity-score-matching methods for none experimental causal studies. The Review of Economics and Statistics, 84(1), 151-161.

Downward, P., \& Riordan, J. (2007). Social interactions and the demand for sport: an economic analysis. Contemporary Economic Policy, 25(4), 518-537.

Downward, P., Hallmann, K., \& Pawlowski, T. (2014). Assessing parental impact on the sports participation of children: A socio-economic analysis of the UK. European Journal of Sport Science, 14(1), 84-90.

Downward, P., Pawlowski, T., \& Rasciute, S. (2014). Does associational behaviour raise social capital? A cross-country analysis of trust. Eastern Economic Journal, 40(2), 150-165.

Eccles, J. S., Barber, B. L., Stone, M., \& Hunt, J. (2003). Extracurricular Activities and Adolescent Development. Journal of Social Issues, 59(4), 865-889.

Eide, E. R., \& Ronan, N. (2001). Is participation in high school athletics an investment or a consumption good? Evidence from high school and beyond. Economics of Education Review, 20(5), 431-442. 
Felfe, C., Lechner, M., \& Steinmayr, A. (2016). Sports and child development. Plos One, forthcoming.

Gerlach, E., \& Brettschneider, W.-D. (2013). Aufwachsen im Sport. Befunde einer 10jährigen Längsschnittstudie zwischen Kindheit und Adoleszenz [Growing up with sport. Findings of a 10-year longitudinal study between childhood and adolescence]. Aachen: Meyer \& Meyer.

Ghuman, S., Behrman, J.R., Borja, J.B., Gultiano, S., \& King, E.M. (2005). Family background, service providers, and early childhood development in the Philippines: proxies and interactions. Economic Development and Cultural Change, 54, 129-164.

Grantham-McGregor, S. (1995). A review of studies of the effect of severe malnutrition on mental development. The Journal of Nutrition, 125(8 Suppl.), 2233S-2238S.

Grantham-McGregor, S. (2002). Linear growth retardation and cognition. Lancet, 359(9306), 542.

Helmers, C., \& Patnam, M. (2011). The formation and evolution of childhood skill acquisition: Evidence from India. Journal of Development Economics, 95(2), 252266.

Hornung, B. R. (2006). Happiness and the pursuit of happiness: A sociocybernetic approach. Kybernetes, 35(3/4), 323-346.

Huang, H., \& Humphreys, B. R. (2012). Sports participation and happiness: Evidence from US microdata. Journal of Economic Psychology, 33(4), 776-793.

Huber, M., Lechner, M., \& Steinmayr, A. (2015). Radius matching on the propensity score with bias adjustment: tuning parameters and finite sample behaviour. Empirical Economics, 49(1), 1-31.

Huber, M., Lechner, M., \& Wunsch, C. (2013). The performance of estimators based on the propensity score. Journal of Econometrics, 175(1), 1-21. 
Humphreys, B. R., \& Ruseski, J. E. (2011). An Economic Analysis of Participation and Time Spent in Physical Activity. The B.E. Journal of Economic Analysis \& Policy, 11(1), $1-38$.

Imbens, G. W. (2004). Nonparametric estimation of average treatment effects under exogeneity: a review. The Review of Economics and Statistics, 86(1), 4-29.

Imbens, G. W., \& Wooldridge, J. M. (2009). Recent developments in the econometrics of program evaluation. Journal of Economic Literature, 47(1), 5-86.

Joffe, M. M., Ten Have, T. R., Feldman, H. I., \& Kimmel, S. E. (2004). Model selection, confounder control, and marginal structural models: review and new applications. The American Statistician, 58(4), 272-279.

Ki-moon, B. (2014a). United Nations Secretary-General's message for the International Day of Sport for Development and Peace on 6 April 2014. Retrieved March 20, 2015, from http://www.un.org/en/events/sportday/2014/sgmessage.shtml

Ki-moon, B. (2014b). United Nations Secretary-General's remarks at the Event "Celebrating Sport for Development and Peace" on 28 April 2014.

Kumra, N. (2008). An assessment of the Young Lives sampling approach in Andhra Pradesh, India, (Technical Note No. 2).

Lechner, M. (2002). Some practical issues in the evaluation of heterogeneous labour market programmes by matching methods. Journal of the Royal Statistical Society, Series A, 165(1), 59-82.

Lechner, M. (2009). Long-run labour market and health effects of individual sports activities. The Journal of Health Economics, 28(4), 839-854.

Lechner, M., Miquel, R., \& Wunsch, C. (2011). Long-run effects of public sector sponsored training in West Germany. Journal of the European Economic Association, 9(4), 742784. 
Lipscomb, S. (2007). Secondary school extracurricular involvement and academic achievement: a fixed effects approach. Economics of Education Review, 26(4), 463472.

Lordan, G., \& Frijters, P. (2013). Unplanned pregnancy and the impact on sibling health outcomes. Health Economics, 22(8), 903-914.

MacKinnon, J. G. (2006). Bootstrap methods in econometrics. The Economic Record, 82, S2-18.

McHale, S., Crouter, A. C., \& Tucker, C. J. (2001). Free-time activities in middle childhood: links with adjustment in early adolescence. Child Development, 72(6), 1764-1778.

Overstreet, S., \& Braun, S. (2000). Exposure to community violence and post-traumatic stress symptoms: Mediating factors. American Journal of Orthopsychiatry, 70(2), 263-271.

Pearson (2013). Peabody Picture Vocabulary Test, Fourth Edition. Retrieved August, 26, 2013, from http://psychcorp.pearsonassessments.com/HAIWEB/Cultures/enus/Productdetail.htm?Pid=PAa30700

Pfeifer, C., \& Cornelißen, T. (2010). The impact of participation in sports on educational attainment - New evidence from Germany. Economics of Education Review, 29(1), 94-103.

Putnam, R. (1993). Making democracy work: Civic traditions in modern Italy. Princeton, NJ: Princeton University Press.

Putnam, R. (1995). Tuning in, tuning out: The strange disappearance of social capital in America. Political Science and Politics, 28(4), 664-683.

Racine, J. S., \& MacKinnon, J. G. (2007). Inference via kernel smoothing of bootstrap Pvalues. Computational Statistics \& Data Analysis, 51(12), 5949-5957.

Rosenbaum, P., \& Rubin, D. (1983). The central role of the propensity score in observational studies for causal effects. Biometrika, 70(1), 41-55. 
Rubin, D. (1979). Using multivariate matched sampling and regression adjustment to control bias in observational studies. Journal of the American Statistical Association, 74(366), 318-328.

Scheerder, J., Taks, M., \& Lagae, W. (2007). Teenage grils' participation in sports. An integrational analysis of socio-cultural predictor variables. European Journal for Sport and Society, 4(2), 133-150.

Seefeldt, V. D., \& Ewing, M. E. (1997). Youth sports in America: An overview. President's Council on Fitness and Sport: Research Digest, 2(11), 1-14.

Stevenson, B. (2010). Beyond the classroom: Using title IX to measure the return to high school sport. The Review of Economics and Statistics, 92(2), 284-301

Victora, C. G., Adair, L., Fall, C., Hallal, P. C., Martorell, R., Ritcher, L., \& Sachdev, H. S., for the Maternal and Child Undernutrition Study Group (2008). Maternal and child undernutrition: consequences for adult health and human capital. Lancet, 371(9609), 340-357.

World Factbook. (2013). Retrieved August, 26, 2013, from https://www.cia.gov/library/publications/the-world-factbook/

Young Lives. (2013). What we do. Retrieved August, 26, 2013, from http://www.younglives.org.uk/what-we-do. 


\section{Tables}

Table 1. Mean values for the outcome variables and t-test significances

\begin{tabular}{|c|c|c|c|}
\hline & $\begin{array}{c}\text { SG member } \\
\text { in } r 3\end{array}$ & $\begin{array}{c}\text { Not SG member } \\
\text { in } r 3\end{array}$ & t-test \\
\hline \multicolumn{4}{|l|}{ Human capital } \\
\hline Vocabulary test (Peabody Picture Vocabulary Test score: 0-200) & 94.03 & 98.36 & $-2.4 * *$ \\
\hline School enrolment (share of enrolled) & $94 \%$ & $93 \%$ & 0.5 \\
\hline \multicolumn{4}{|l|}{ Social capital } \\
\hline Neighbourhood trust (share of "agree" \& "strongly agree”) & $32 \%$ & $31 \%$ & 0.2 \\
\hline Friends support (share of "agree" \& "strongly agree") & $69 \%$ & $58 \%$ & $2.1 * *$ \\
\hline Respect by children (share of "agree" \& "strongly agree") & $79 \%$ & $82 \%$ & -0.7 \\
\hline Safe environment (share of "agree" \& "strongly agree") & $51 \%$ & $44 \%$ & 1.4 \\
\hline \multicolumn{4}{|l|}{ Subjective well-being } \\
\hline Satisfaction with life (Cantril ladder: 1 “dissatisfied” to 9 “satisfied”) & 6.50 & 6.04 & $2.7^{* * *}$ \\
\hline \multicolumn{4}{|l|}{ Health capital } \\
\hline Health status (mean of 1 “very poor” to 5 “very good”) & 3.91 & 3.72 & $2.8^{* * *}$ \\
\hline Body Mass Index (weight / squared height) & 21.05 & 21.10 & -0.2 \\
\hline \multicolumn{4}{|l|}{ Other group participation } \\
\hline After school club (share of members) & $3 \%$ & $6 \%$ & -1.6 \\
\hline Religious group (share of members) & $5 \%$ & $9 \%$ & -1.4 \\
\hline School club (share of members) & $2 \%$ & $2 \%$ & -0.2 \\
\hline Youth group (share of members) & $4 \%$ & $3 \%$ & -0.1 \\
\hline Observations & 118 & 540 & \\
\hline
\end{tabular}


Table 2. Descriptive statistics and selected average marginal effects of the probit model for the variables of the selection process into sports group participation

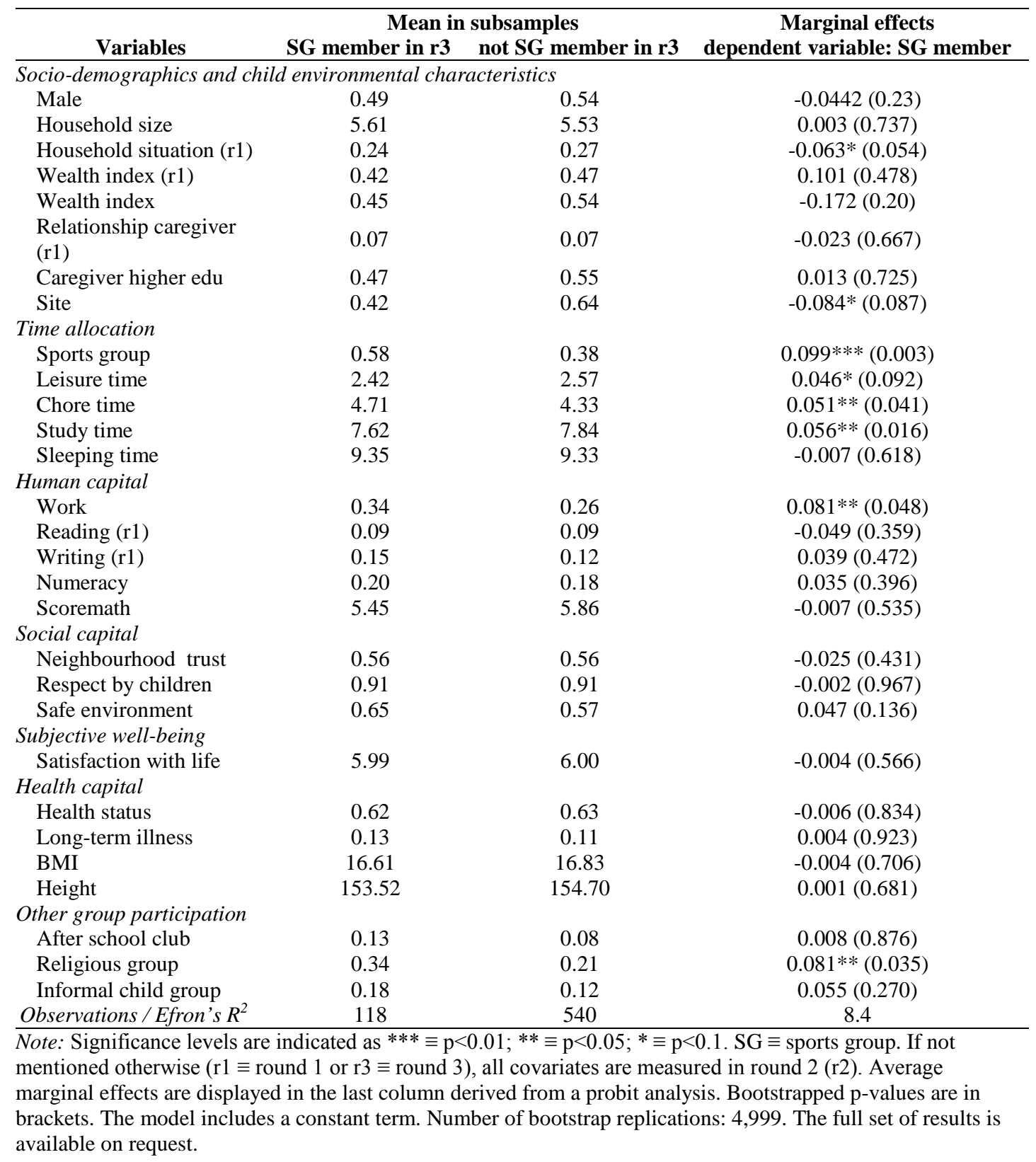


Table 3. Radius matching results of sports group participation

\begin{tabular}{|c|c|c|c|}
\hline & ATE & ATET & ATENT \\
\hline \multicolumn{4}{|l|}{ Human capital } \\
\hline Vocabulary test (Peabody Picture Vocabulary Test score: $0-200$ ) & $-0.617(0.727)$ & $-3.419(0.441)$ & $-0.009(0.989)$ \\
\hline School enrolment (dummy; 1 if "enrolled in school”) & $0.030(0.114)$ & $0.024(0.564)$ & $0.031(0.122)$ \\
\hline \multicolumn{4}{|l|}{ Social capital } \\
\hline Neighbourhood trust (dummy; 1 if "agree" \& "strongly agree") & $-0.008(0.906)$ & $0.023(0.802)$ & $-0.015(0.825)$ \\
\hline Friends support (dummy; 1 if "agree" \& "strongly agree") & $0.121^{* *}(0.044)$ & $0.136 *(0.061)$ & $0.118 *(0.083)$ \\
\hline Respect by children (dummy; 1 if "agree" \& "strongly agree") & $-0.008(0.858)$ & $0.007(0.907)$ & $-0.011(0.821)$ \\
\hline Safe environment (dummy; 1 if "agree" \& "strongly agree") & $0.048(0.451)$ & $0.055(0.441)$ & $0.047(0.516)$ \\
\hline \multicolumn{4}{|l|}{ Subjective well-being } \\
\hline Satisfaction with life (Cantril ladder: 1 "dissatisfied" to 9 "satisfied") & $0.287(0.168)$ & $0.413(0.128)$ & $0.259(0.248)$ \\
\hline \multicolumn{4}{|l|}{ Health capital } \\
\hline Health status (mean of 1 “very poor” to 5 “very good”) & $0.303^{* * *}(0.001)$ & $0.246 * *(0.018)$ & $0.315^{* * *}(0.004)$ \\
\hline Body Mass Index (weight / squared height) & $0.279(0.381)$ & $0.031(0.939)$ & $0.333(0.384)$ \\
\hline \multicolumn{4}{|l|}{ Other group participation } \\
\hline Member of an after school club (dummy; 1 if “yes”) & $-0.028(0.457)$ & $-0.040(0.224)$ & $-0.026(0.565)$ \\
\hline Member of an religious group (dummy; 1 if “yes”) & $-0.056(0.100)$ & $-0.108(0.193)$ & $-0.045(0.266)$ \\
\hline Member of an school club (dummy; 1 if “yes”) & $0.017(0.496)$ & $-0.063(0.545)$ & $0.034(0.357)$ \\
\hline Member of an youth group (dummy; 1 if "yes") & $-0.014(0.293)$ & $0.015(0.568)$ & $-0.020(0.156)$ \\
\hline
\end{tabular}

No. of observations: 658

No. of treated: 118 (17.93\% of observations)

Common support: 650 (Share in common support: 98.78\%)

Note: Significance levels are indicated as $* * * \equiv \mathrm{p}<0.01 ; * * \equiv \mathrm{p}<0.05 ; * \equiv \mathrm{p}<0.1$. p-values (in brackets) obtained from 4,999 bootstrap replications as the share of absolute bootstrap t-statistics that are larger than the absolute t-statistic in the original sample. The results are based on a version, which uses weighted logits instead of weighted OLS for the binary outcomes (weights used for inference take bias adjustment not into account). 


\section{Appendix}

Table A.1. Large-scale empirical studies exploring possible effects of child and youth sports participation on their human capital, social capital, subjective well-being and health

\begin{tabular}{|c|c|c|c|}
\hline Study & Country and Data & Methods & Results \\
\hline $\begin{array}{l}\text { Barron, Ewing, } \\
\text { and Wadell } \\
(2000)\end{array}$ & $\begin{array}{l}\text { USA, National } \\
\text { Longitudinal Survey of } \\
\text { Youth (NLSY; } n=1,047) \\
\text { and of High School Class } \\
\text { (NLS-72; } n=3,014)\end{array}$ & $\begin{array}{l}\text { Two-period } \\
\text { model of time } \\
\text { allocation (probit } \\
\text { model) }\end{array}$ & $\begin{array}{l}\text { Human capital: Athletic participation directly } \\
\text { affects wages and educational attainment (EA). But } \\
\text { effects appear to reflect differences across } \\
\text { individuals in ability or value of leisure. }\end{array}$ \\
\hline $\begin{array}{l}\text { Eide and Ronan } \\
\text { (2001) }\end{array}$ & $\begin{array}{l}\text { USA, High School and } \\
\text { Beyond data set (HSB) } \\
(n=11,577)\end{array}$ & $\begin{array}{l}\text { Ordinary least } \\
\text { squares and } \\
\text { instrumental } \\
\text { variable }\end{array}$ & $\begin{array}{l}\text { Human capital: Sports participation has a neg. } \\
\text { effect on the EA of white male student athletes, a } \\
\text { pos. effect on the EA and earnings of black male } \\
\text { student athletes, and a pos. effect on the EA of } \\
\text { white female student athletes. }\end{array}$ \\
\hline $\begin{array}{l}\text { Eccles, Barber, } \\
\text { Stone, and Hunt } \\
\text { (2003) }\end{array}$ & $\begin{array}{l}\text { Michigan, USA MSALT } \\
(\mathrm{n}=1,259)\end{array}$ & $\begin{array}{l}\text { Longitudinal } \\
\text { regression } \\
\text { analysis }\end{array}$ & $\begin{array}{l}\text { Human capital: Participation in most } \\
\text { extracurricular activities leads to better educational } \\
\text { outcomes by controlling for social class, gender and } \\
\text { intellectual aptitude. Participation on school sports } \\
\text { teams increased educational outcomes, but higher } \\
\text { drinking rates, too. }\end{array}$ \\
\hline $\begin{array}{l}\text { Lipscomb } \\
\text { (2007) }\end{array}$ & $\begin{array}{l}\text { USA, National Education } \\
\text { Longitudinal Study } \\
\text { (NELS) }(n=16,305)\end{array}$ & $\begin{array}{l}\text { Fixed effects } \\
\text { strategy }\end{array}$ & $\begin{array}{l}\text { Human capital: Athletic and club participation are } \\
\text { associated with an increase in math test scores and } \\
\text { an increase in Bachelor's degree attainment } \\
\text { expectations. }\end{array}$ \\
\hline $\begin{array}{l}\text { Stevenson } \\
(2010)\end{array}$ & $\begin{array}{l}\text { National Center for } \\
\text { Education Statistics } \\
\text { (NCES) and Public Use } \\
\text { Micro Sample (PUMS) (n } \\
\text { varies per data set) }\end{array}$ & $\begin{array}{l}\text { Instrumental } \\
\text { variables }\end{array}$ & $\begin{array}{l}\text { Human capital: Analysis across states in changes } \\
\text { between pre- and post-legislation reveals that a rise } \\
\text { in state sports participation for females generates an } \\
\text { increase in female college attendance and in labour } \\
\text { force. }\end{array}$ \\
\hline $\begin{array}{l}\text { Pfeifer and } \\
\text { Cornelißen } \\
(2010)\end{array}$ & GSOEP $(n=6,050)$ & $\begin{array}{l}\text { Generalized } \\
\text { ordered probit } \\
\text { models }\end{array}$ & $\begin{array}{l}\text { Human capital: After controlling for important } \\
\text { variables, a significant and positive effect of sport } \\
\text { on educational attainment could be found. }\end{array}$ \\
\hline $\begin{array}{l}\text { Felfe, Lechner, } \\
\text { and Steinmayr } \\
\text { (2016) }\end{array}$ & $\begin{array}{l}\text { KiGGS, GCP and } \\
\text { information on the } \\
\text { available sports facilities } \\
(\mathrm{n}=5,632)\end{array}$ & $\begin{array}{l}\text { Matching } \\
\text { estimation } \\
\text { strategy and } \\
\text { instrumental } \\
\text { variable (IV) }\end{array}$ & $\begin{array}{l}\text { Human capital, subjective well-being and health: } \\
\text { Sports club participation of children in Germany } \\
\text { aged } 3 \text { to } 10 \text { years has a positive effect on skill } \\
\text { development (cognitive and non-cognitive), general } \\
\text { well-being and health. }\end{array}$ \\
\hline $\begin{array}{l}\text { Gerlach and } \\
\text { Brettschneider } \\
\text { (2013) }\end{array}$ & $\begin{array}{l}\text { Germany, } \\
\text { Longitudinal Study of } \\
\text { children in a region in } \\
\text { Germany (Paderborn) } \\
(\mathrm{n}=1,637)\end{array}$ & Variance analysis & $\begin{array}{l}\text { Social capital, subjective well-being and health: } \\
\text { Sports club participation of children and } \\
\text { adolescents has a significant positive effect on } \\
\text { social acceptance and respect by peers and well- } \\
\text { being. However, there is no significant positive } \\
\text { effect on obesity. }\end{array}$ \\
\hline
\end{tabular}


Table A.2. General information on Peru

\begin{tabular}{ll}
\hline Location (population) & West of South America (29.8 million) \\
Population (urban/rural) & 77 per cent in urban areas (USA: 82\%) \\
$\begin{array}{l}\text { Poverty (\% of pop. living below poverty line) } \\
\text { Health }\end{array}$ & 27.8 per cent (USA: 15.1\%) \\
$\quad$ Life expectancy (in years) & Men: 71, women: 75 (USA: men: 77, women 81) \\
$\quad$ Infant mortality rate (per 1,000 live births) & 21 deaths (USA: 6.2) \\
$\quad$ Health expenditure & $5.1 \%$ of GDP (GDP: \$ 292.2 billion in 2010) (USA: 17.9\%) \\
Education & a) 6 years \\
$\quad$ Age of school enrolment & b) 12 grades \\
$\quad$ Grades ( $1^{\text {st }}$ and $2^{\text {nd }}$ education) & c) 90 per cent and 97 per cent for youth (15-24 years) (USA: 99\%) \\
Literacy rate & Source: World Factbook (2013) https://www.cia.gov/library/publications/download/download-2013/
\end{tabular}

Table A.3. Information on sport and sports systems in Peru

\begin{tabular}{ll}
\hline $\begin{array}{l}\text { Most popular sport } \\
\text { General organization of sports groups }\end{array}$ & Football \\
& Mainly football clubs \\
& Great demand for sports clubs from children; clubs have to be paid to be \\
& member; public parks with sports facilities (pay for access) \\
Aim of sports groups & Practicing, preparing for competitions, playing sports in general \\
Degree of organization in sports groups & There are coaches in the sports groups organized in clubs. \\
\hline $\begin{array}{l}\text { Source (contact persons): Virginia Rey-Sánchez (Directora de comunicaciones) and Mariluz Aparicio (Asistente de } \\
\text { comunicaciones), Estudio Niños del Milenio (www.ninosdelmilenio.org) }\end{array}$
\end{tabular}


Table A.4. Description of confounding variables (taken from round 1 and 2; only "height" taken from round 3)

\begin{tabular}{|c|c|c|}
\hline Variables & Label & Scale \\
\hline \multicolumn{3}{|c|}{ Socio-demographics and child environmental characteristics } \\
\hline Male & Gender of the child. & Dummy (1 if "male") \\
\hline Site & Site where the child lives. & Dummy (1 if "urban") \\
\hline Household size & Number of household members. & Metric \\
\hline Household situation & Household situation (wealth) compared to others. & Dummy (1 if "poorer") \\
\hline Wealth index (wi) & Measures the socioeconomic status of households. & Metric (value between 0 and 1 ) \\
\hline Relationship caregiver & Relationship of caregiver and child. & $\begin{array}{l}\text { Dummy ( } 1 \text { if " mother is not primary } \\
\text { caregiver ") }\end{array}$ \\
\hline Caregiver higher edu & $\begin{array}{l}\text { Caregiver completed secondary or post-secondary } \\
\text { school or university. }\end{array}$ & Dummy (1 if "completed") \\
\hline \multicolumn{3}{|l|}{ Time allocation } \\
\hline Sports group & Sports group membership in round 2 . & Dummy (1 if "yes") \\
\hline Leisure time & Time spent for general leisure on a typical day. & Metric \\
\hline Chore time & $\begin{array}{l}\text { Time spent for caring for others, domestic tasks, and } \\
\text { family farm or business on a typical day. }\end{array}$ & Metric \\
\hline Study time & $\begin{array}{l}\text { Time spent at school and for studying outside school } \\
\text { on a typical day. }\end{array}$ & Metric \\
\hline Sleeping time & Time spent for sleeping on a typical night. & Metric \\
\hline \multicolumn{3}{|l|}{ Human capital } \\
\hline Work & Has child done paid work in last 12 months? & Dummy (1 if "yes") \\
\hline Reading & Child can’t read letters, words or sentences. & Dummy ( 1 if "yes") \\
\hline Writing & Child can't write sentences. & Dummy ( 1 if "yes") \\
\hline Numeracy & Answer to the calculation 2 times 4 . & Dummy (1 if "wrong") \\
\hline Scoremath & Mathematic achievement test. & Metric (scores between 0 and 10 ) \\
\hline \multicolumn{3}{|l|}{ Social capital } \\
\hline Neighbourhood trust & Most people in my neighbourhood can be trusted. & Dummy (1 if "agree" \& "strongly agree") \\
\hline Respect by children & Other children in my class treat me with respect. & Dummy (1 if "agree" \& "strongly agree") \\
\hline Safe environment & I feel safe when I go out of the house on my own. & Dummy (1 if "agree" \& "strongly agree") \\
\hline \multicolumn{3}{|l|}{ Subjective well-being } \\
\hline Satisfaction with life & Current position on ladder. & $\begin{array}{l}\text { Cantril ladder (1 “dissatisfied” to } 9 \\
\text { “satisfied”) }\end{array}$ \\
\hline \multicolumn{3}{|l|}{ Health capital } \\
\hline Health status & Health compared to other children. & Dummy (1 if "worse") \\
\hline Long-term illness & Child has long time health problems. & Dummy (1 if "yes") \\
\hline BMI (Body Mass Index) & Weight / squared height & Metric \\
\hline Height & Height of the child & \\
\hline \multicolumn{3}{|l|}{ Other group participation } \\
\hline After school club & Member of an after school club & Dummy (1 if "yes") \\
\hline Religious group & Member of a religious group & Dummy ( 1 if "yes") \\
\hline Informal child group & Member of an informal child group & Dummy ( 1 if "yes") \\
\hline
\end{tabular}

